\title{
Lubricants used in internal combustion engines in times of downsizing
}

\author{
Sebastian Kilimnik ${ }^{1}$, Robert Polasik ${ }^{1}$ \\ ${ }^{1}$ Politechnika Bydgoska im. Jana i Jędrzeja Śniadeckich w Bydgoszczy, Polska
}

\begin{abstract}
The operation of the internal combustion engine leads to the production of exhaust gases harmful to the natural environment. The introduced standards of the European exhaust emission standard aim, among other things, to reduce $\mathrm{CO} 2$ emissions. Such assumptions are related to the reduction of fuel consumption of internal combustion engines in vehicles. This means the need to make structural changes in the produced engines, and thus reduce the displacement while maintaining high power and torque. Engines constructed in this way require the use of individually selected oils and maintaining appropriate service intervals for their replacement.
\end{abstract}

\section{Introduction}

The operating energy of the internal combustion engine is obtained through the process of burning hydrocarbon fuels. A side effect of this work is the formation of exhaust gases, which include: carbon dioxide $\left(\mathrm{CO}^{2}\right)$, carbon monoxide $(\mathrm{CO})$, nitrogen compounds $\left(\mathrm{NO}_{\mathrm{x}}\right)$, hydrocarbons $(\mathrm{HC})$, particulate matter $(\mathrm{PM})$, lead compounds $(\mathrm{Pb})$, sulfur compounds $\left(\mathrm{SO}^{2}\right)$ and $\left(\mathrm{SO}^{3}\right)$ [10]. As the number of vehicles increases, so does the emission of gases entering the Earth's atmosphere. Road transport is as much as $20 \%$ of total CO2 emissions in Europe. Taking into account the speed of development and the constantly growing number of vehicles, it was necessary to introduce exhaust emission standards. They allow for stricter emission criteria for newly produced cars. The current $\mathrm{CO} 2$ emission standard is $95 \mathrm{~g} / \mathrm{km}$, which translates into a consumption of 3.8 liters of fuel per $100 \mathrm{~km}$ [4]. The average value for a given manufacturer is calculated based on all cars produced. In addition to the introduction of electric and hybrid vehicles, it is necessary to reduce emissions from typical internal combustion engines. Reducing the amount of exhaust gases is possible due to the reduction of fuel consumption by power units, which is associated with the need for design changes. Changes in carbon dioxide emission limits are shown in Figure 1.

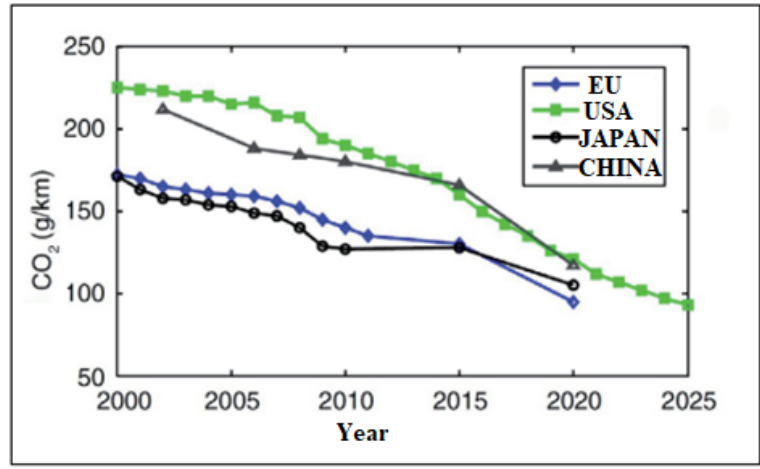

Fig.1. Reduction of $\mathrm{CO}_{2}$ emissions in individual years [1].

Ways to achieve lower fuel consumption by the unit are:

- the use of start-stop systems,

- deactivation of cylinders during uniform operation,

- design of aerodynamic bodies,

- reduction of the total weight of the vehicle,

- reduction of electricity consumption (use of LED lights, daytime running lights),

- use of tires with reduced rolling resistance 
- use of appropriate cooling of both the power unit and operating fluids,

- recovery of braking energy,

- the use of modern driveline systems,

- reduction of cylinder capacity and size (weight of the engine), the so-called Downsizing,

- the use of properly selected lubricants that allow for energy efficiency.

\section{Impact of the internal combustion engine on the lubricant}

Expectations for modern internal combustion engines, on the one hand, are imposed by ecological standards, and on the other hand, they must be adapted to the needs of users. The power unit must provide adequate performance throughout its service life and be durable with moderate fuel consumption and low operating costs. With these assumptions, it is necessary to use solutions such as:

-direct fuel injection,

-air boost with a turbine or compressor,

-exhaust gas recirculation,

-modern catalysts and exhaust gas filters.

All additional elements result in greater expansion and complexity of the engine design. The need to reduce the weight of the components reduces their dimensions, and the higher compression pressure contributes to greater engine effort. The necessity of maintaining or improving operating parameters in new engine designs forces the elements to cooperate under higher loads, being exposed to higher temperatures. This also increases the load on the engine oil. The figure below shows a modern four-cylinder internal combustion engine with a capacity of $2000 \mathrm{~cm}^{3}$ and a power of $421 \mathrm{hp}$ and $500 \mathrm{Nm}$.

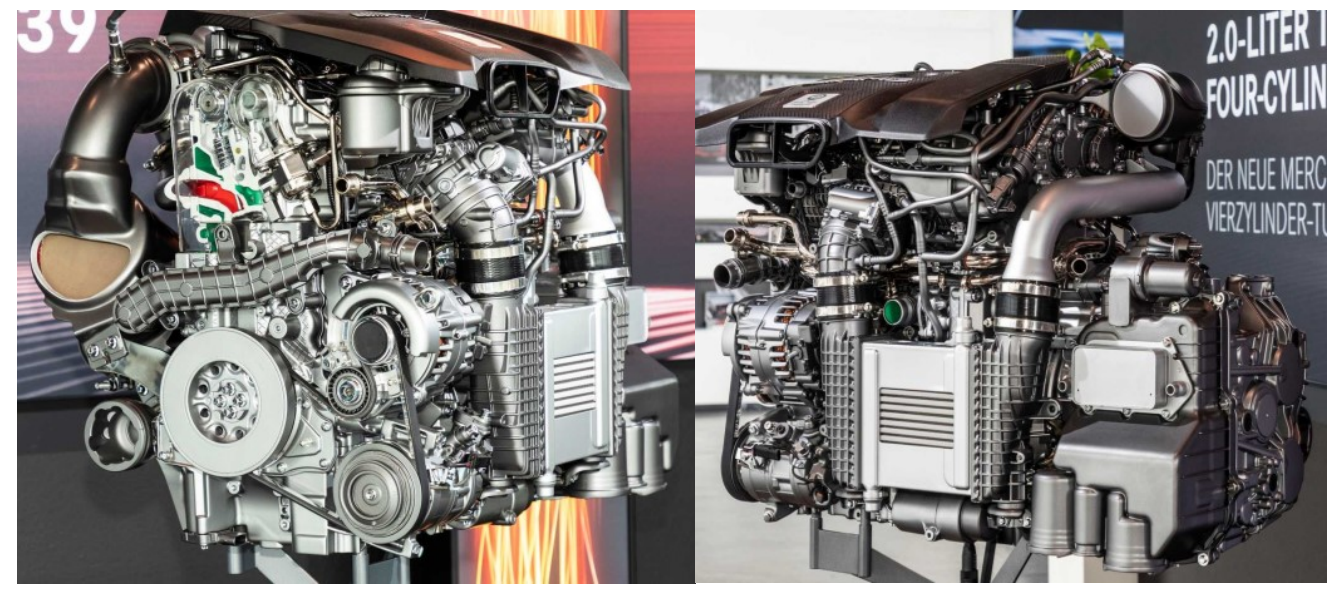

Fig.2. Engine produced Mercedes-Benz model m139 [6].

The creation of modern engines is therefore associated with the need to adjust or create oil that meets the construction requirements of the power unit. Factors influencing the need to use advanced engine oils are, among others, increased temperature of the engine or its components. The high combustion temperature of the mixture and structurally developed heads with small diameter cooling holes contribute to the increase in temperatures. For engine oil, this is not insignificant. A lubricant at $100^{\circ} \mathrm{C}$ has a higher oxidation capacity and rapid decomposition and oxidation processes occur at temperatures above $140^{\circ} \mathrm{C}$ of the lubricant. The oil is then thickened and its acid number is increased. Increasing the saturation of oil with oxidation products reduces the efficiency of dispersing and detergency additives, which in turn causes the precipitation of tar and sludge on the engine components. The impact of nitrogen oxides formed during the combustion process of the lean mixture also contributes to the deposition of sludges. Any scoops reduce heat dissipation from the engine, therecing the process of oil consumption. Blows to the crankcase also have a negative effect on the oil. This is the phenomenon of ingress of exhaust gases formed in the process of combustion of the mixture under the piston, into the crankcase. Exhaust gases containing nitrogen oxides, sulfur oxides, hydroxide and soot in contact with oil have a negative effect on it. Additives refining oil in contact with heated exhaust gases decompose, and the oil base is thickened, which promotes the precipitation of, among others, antioxidant additives. Figure 3 below shows an extreme case of excessive sludge deposition on the head elements and the chain and camshafts. 


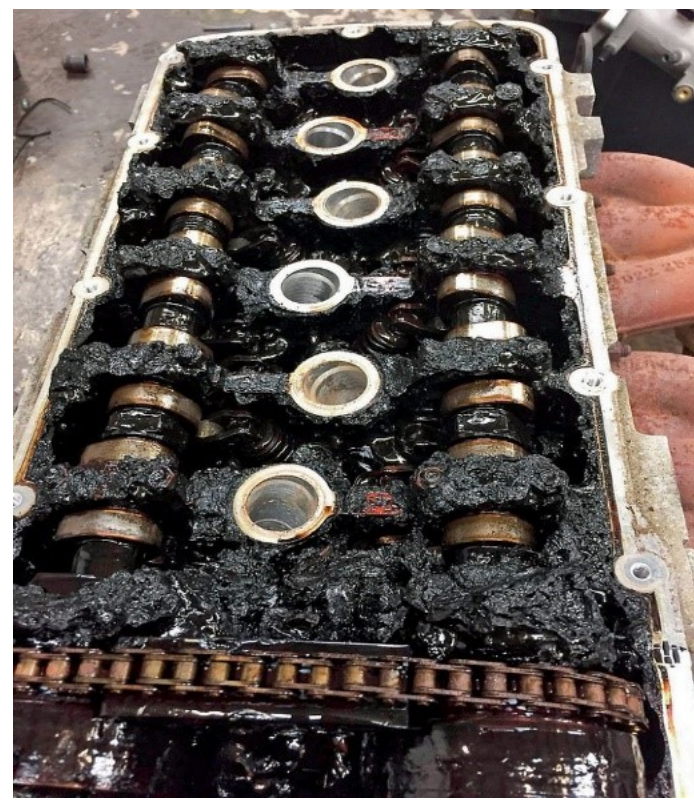

Fig.3. Sludge deposition on elements inside the engine [7].

Engine oils are also exposed to harsh operating conditions. The following are the conditions under which their quality may deteriorate due to the formation of sludges in the engine: engine)

- short-term engine operation (driving a car on short distances causing frequent heating and cooling of the

- engine underheating (engine idling due to e.g. road congestion) - frequent starting of a cold engine in low temperature conditions

- different operating conditions (high load resulting in an increase in engine temperature, and then rapid cooling, an example may be operation in mountainous areas)

The harsh operating conditions presented above cause the accumulation of water inside the engine, which then goes into the engine oil. Even trace amounts of water in the lubricant worsen its properties, increasing its viscosity and worsening circulation in oil channels. The consequence of this may be an increase in the temperature of the oil, its overheating and excessive oxidation [2].

The oil designer must therefore create an oil that:

- performs the function of a heat dissipation agent (about 5-10\% of the heat generated by the power unit is generated in friction nodes, and the remaining part as a result of the fuel combustion process),

- is characterized by resistance to oxidation,

- keeps the engine components clean, reducing the formation of sludges,

- protects against corrosion,

- has sealing properties,

- does not show negative effects when working with rubber elements and other types of plastics (dissolving elements)

- shows resistance to foaming.

The development of technology in the production process of engine oils has made it possible to use engine oils with lower viscosity classes. Many leading vehicle manufacturers suggest using oil with SAE viscosity class $0 \mathrm{~W}$ 20 , which contributes to lower fuel consumption. For the cooperating engine components, however, it is important that the grease is characterized by viscosity, which at high temperatures of its operation will allow the preservation of the oil film.

\section{Friction and lubrication in the internal combustion engine}

The energy consumed by the friction process of the cooperating elements of the internal combustion engine is about $7 \%$ of the energy contained in the fuel. Mainly from the friction nodes are:

- piston - cylinder,

- piston rings - cylinder,

- crankshaft bearings,

- connecting rod bearings- crankshaft - piston pin,

- timing system, 


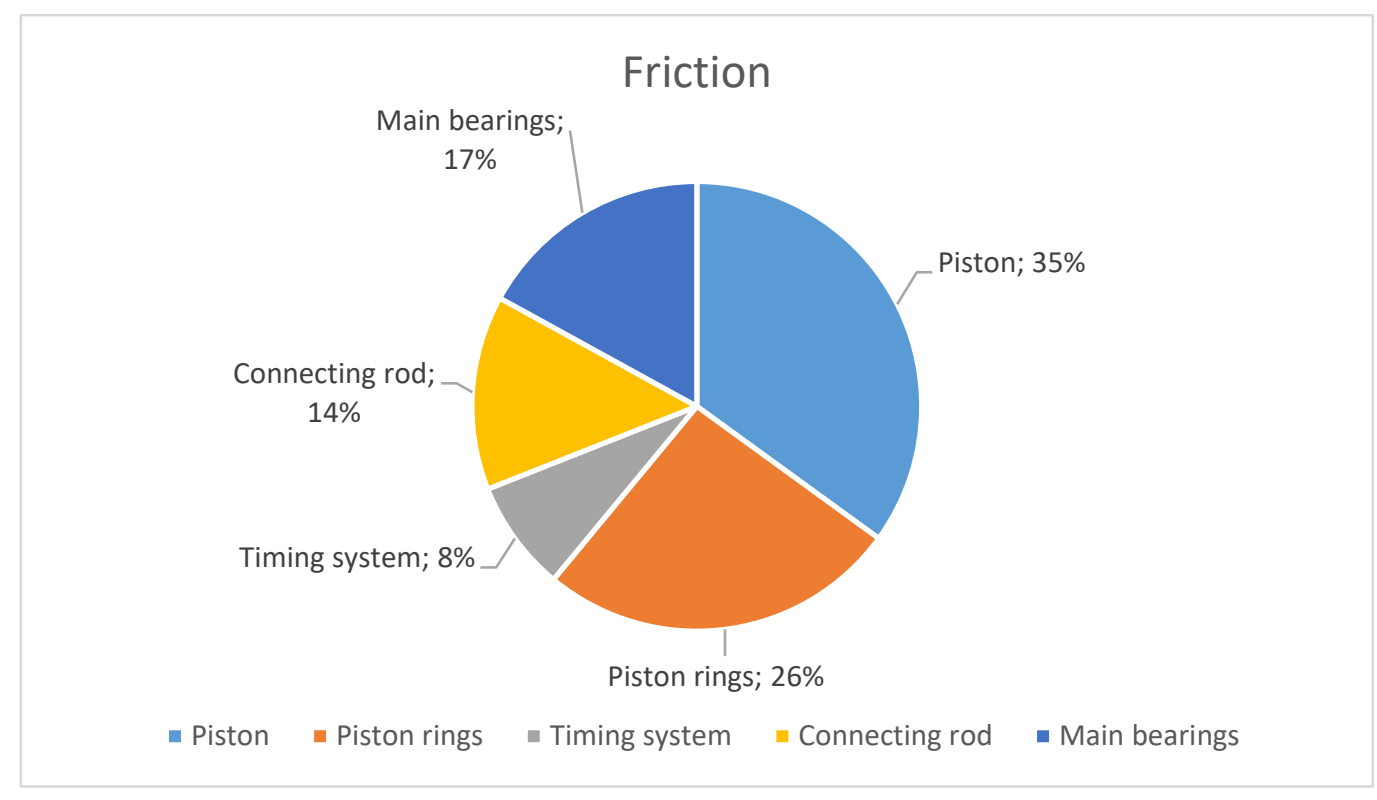

Fig.4. Percentage of friction of the cooperating components of the engine [2].

So that during the operation of the elements there is no contact between metal and metal, it is necessary to use grease. Engine oil therefore performs the function of protecting the elements against loss. The resulting oil film separates the cooperating elements from each other, reduces the friction that occurs, which reduces the wear of these elements. Separating the working elements with a layer of oil film is called hydrodynamic lubrication. Interruption of the continuity of the oil film and metal-metal contact are referred to as boundary lubrication. It leads to excessive wear of engine components. One example of limit friction can be a cold start. Taking into account the different types of movement of the cooperating elements, there is a variety of lubrication. Bearings and engine seals are mainly lubricated hydrodynamically. Mixed lubrication, which is a combination of hydrodynamic or elastohydrodynamic and boundary lubrication, occurs in the timing system. Elastohydrodynamic lubrication occurs in three contact groups. An example of the first is the piston-cylinder work, where there is sliding contact. Another is rolling contact, which occurs, among others, in ball bearings. The third case is slidingrolling contact appearing with the cooperation of gears. Lubrication phenomena in the piston-cylinder system are more complex. It can be determined that in $40 \%$ there is hydrodynamic lubrication, in $40 \%$ elastohydrodynamic, in $10 \%$ mixed lubrication, and $10 \%$ is border lubrication [3,9].

Figures 5 and 6 below show the hydrodynamic and limit lubrication respectively. In the upper and lower parts, the drawings show the cooperating elements described as 1 and 3 with the directions of movement marked with arrows, the middle part with the number 2 indicates the oil layer.

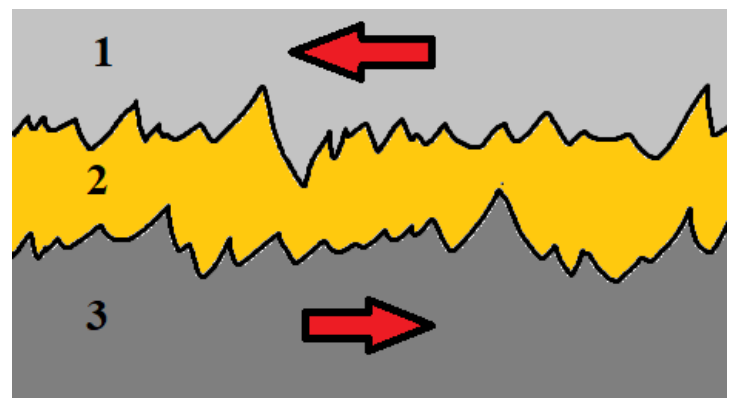

Fig.5. Lubrication continuity - hydrodynamic lubrication [8]. 


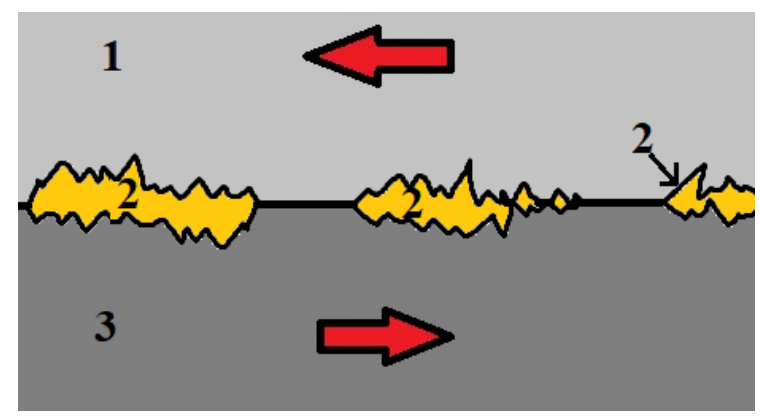

Fig. 6. Local contact of elements (metal-metal) - boundary lubrication [8].

The movement of oil layers relative to each other is referred to as viscosity. Important parameters are kinematic viscosity and viscosity index. Engine oil is operated at different temperatures, starting from starting, where the oil and engine components are cold, until the operating temperature is reached. The temperature difference is several dozen degrees. That is, the average viscosity should not be too high at the time of starting the engine and too low during its operation $[5,12]$. Thus, oil additives in the form of viscosity modifiers are used.

They allow to:

- reduction of viscosity changes as a function of temperature,

- starting the engine at low temperatures,

- maintaining engine life in conditions of limit lubrication,

- maintaining the cleanliness of engine components,

- reducing the increase in viscosity due to soot entering the oil,

- maintaining the durability of seals

- performing the function of hydraulic fluid by the oil.

Due to the friction processes taking place in the engine components, it is important to maintain the durability parameters of the unit using oils that allow to reduce energy consumption. In order to properly categorize oils as energy-efficient, engine tests have been developed to compare fuel consumption using oils of different viscosities comparing them to a reference oil. The American Scientific Institute and the Association of European Automobile Manufacturers use tests on test benches to assess the energy efficiency of the oil. In the case of research in Europe, it is a dynamometer with a Mercedes engine model M111 with a displacement of $2000 \mathrm{~cm}^{3}$. The reference oil for testing is CEC RL-191 with a viscosity of $15 \mathrm{~W} 40$. The reduction in fuel consumption is in terms of percentage compared to the reference oil. From the results shown in Figure 7, it can be seen that oils with viscosity grades $0 \mathrm{~W}-10$ and $0 \mathrm{~W}-20$ are characterized by the greatest reduction in fuel consumption compared to the reference oil. Oils with such fuel economy parameters are classified as "Fuel Economy". An example of a manufacturer that advertises its oils with a given designation is TOYOTA.

The following is a drawing from Shell's research, where grease with viscosity class $0 \mathrm{~W} 10$ is a concept for a new type of oil.

A factor influencing the efficiency of oil in reducing fuel consumption is the design of the engine. The number of cylinders, the type of timing and valve tappets used are important. Using the wrong oil to lubricate a structurally advanced engine can cause accelerated and even emergency wear. The wrong oil will not fully remove impurities, forming deposits in the form of sludges. The use of oil with too high viscosity class in new constructions will delay its flow through the oil channels, and then cause improper lubrication of the contact points of the elements (especially when starting the engine). Slow flow will reduce heat dissipation, which will contribute to excessive lubricant consumption $[9,10]$.

Taking into account the factors presented above, the individual selection of engine oil with energy-saving properties must be based on:

- selection of the appropriate viscosity class for the engine design,

- maintaining proper circulation by the oil,

- effective lubrication,

- effective heat dissipation,

- the ability to disperse sediments,

- cleaning impurities formed in the combustion process, oil oxidation products. 


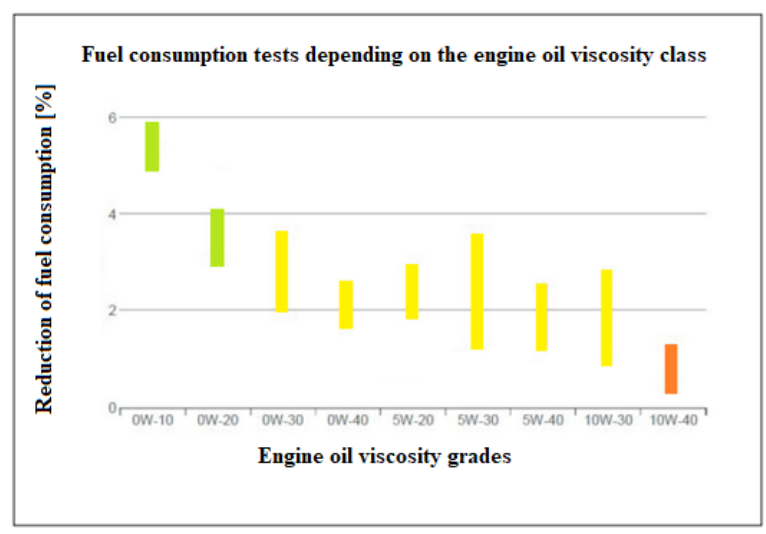

Fig.7. Testing of oils with different viscosity grades in the M111 test [9].

A poorly matched oil change life can have a negative impact on the energy efficiency of the oil. Too long an interval between engine oil changes can lead to adverse phenomena. Excessively long operation of the oil results in a rapid deterioration of its properties, the formation of degradation products in the form of lacquers, resins and sludges. By evaporating in the process of exploitation of light fractions and increasingly intensive oxidation, viscosity increases. Increased viscosity can lead to oil overheating, increased circulation resistance, deterioration of lubrication, increased deposits, increased engine operating temperature and the entry of aggressive exhaust gases with elevated temperature into the crankcase. This means that excessive extension of the service life causes the loss of its alkaline reserve, increased acidity, degradation of refining additives and the formation of resins and sludges.

Performing engine oil changes in cars that achieve mileages much lower than those assumed by the manufacturer may generate unnecessary costs for the user and even contribute to increasing environmental pollution due to the need to dispose of chemical waste.

\section{Summary}

Due to the ever-increasing number of vehicles, road transport contributes significantly to greenhouse gas emissions. The introduced exhaust emission standards are becoming more and more stringent, which translates into the need to develop automotive technology based, among other things, on reducing the displacement of internal combustion engines. In order to reduce fuel consumption while maintaining engine parameters related to the power and durability of the unit, designers must also adjust the lubricants. Modern engines require individual selection of oil, taking into account its viscosity class, engine heat loads, exhaust gas blows into the crankcase, the need for proper flow and lubrication in various operating conditions. The development of research on engine oils has made it possible to reduce friction and minimize losses associated with oil rheology. This allowed the use of oils with SAE 0W-20 viscosity class in everyday use, which significantly contributed to reducing fuel consumption. Current research concerns oils with very low viscosities (SAE 0W-12, 0W8).

However, it should be remembered that the aging, degradation and ingress of pollutants occurring during operation cause changes in its functional properties. In order to ensure the proper functioning of a modern internal combustion engine and take care of the natural environment, it is reasonable to determine the appropriate lubricant life. The complexity of the power unit design requires determining the mileage value, which will allow its operation in the right lubrication conditions, will be ecological not only reducing fuel consumption, but also reducing the amount of used oil going to disposal. Such a parameter will contribute to a complete reduction in operating costs for the final user.

\section{References}

1. Mock P. (2012) European CO2 emission performance standards for passenger cars and light commercial vehicles, Technical report, The International Council on Clean Transportation

2. de Vincente J, Stokes RJ, Spikes HA. Rolling and sliding friction in compliant, lubricated contact. Journal of Engineering Tribology, Proceeding of the Institution of Mechanical Engineers 2006;220:J55-63

3. Rosenberg RC. General friction considerations for engine design. SAE Paper 821576; 1981, p. 59-70.

4. https://theicct.org/sites/default/files/publications/EU-LCV-CO2-2030_ICCTupdate_201901.pdf (10.2021)

5. Sheahan T.J, Romig W.S., "Lubricant Related Fuel Savings in Short Trip, Cold Weather Service”, SAE 750676 
6. https://motostacja.com/blog/newsy/mercedes-benz-zaprezentowal-najmocniejszy-seryjny-czterocylindrowysilnik.html (10.2021)

7. https://www.auto-swiat.pl/porady/eksploatacja/oleje-long-life-nie-ma-olejow-wytrzymujacych-30-tys$\mathrm{km} / \mathrm{tdqt} 266(10.2021)$

8. Own elaboration Sebastian Kilimnik

9. Oleksiak S., Energooszczędne oleje silnikowe do samochodów osobowych. Prace Naukowe Instytutu Nafty i Gazu (2015) nr 201, p.34-51.

10. M. Markiewicz, Ł. Muslewski, The impact of powering an engine with fuels from reneweble energy sources inclouding its softwere modification on a drive unit performance parameters. Sustainaibility, 23 (2019)

11. B. Landowski, M. Baran, Analysis of selected results of engine oil tests, MATEC Web of Conferences 302, 01010 (2019), 18th International Conference Diagnostics of Machines and Vehicles, pp.1-7 (2019), https://doi.org/10.1051/matecconf/201930201010

12. B. Landowski, M. Baran, Analysis of changes in the value of selected lubricant characteristics during use, MATEC Web of Conferences 302, 01009 (2019), 18th International Conference Diagnostics of Machines and Vehicles, pp.1-8 (2019), https://doi.org/10.1051/matecconf/201930201009 